\title{
A Current Awareness Service Using Microcomputer Databases and Electronic Mail
}

\section{John T. Butler}

\begin{abstract}
Libraries are challenged economically to provide customized services to faculty and researchers who have ongoing needs for specialized information. This report describes a pilot current awareness service which provided individual faculty with weekly searches of recently published literature, while incurring relatively low costs. Search results were generated using microcomputer databases and were transmitted electronically to faculty using a combination of mainframe computing, a high-speed campus network, and electronic mail. The methodology, which incorporated an automatic mailing program, is detailed. Costs are analyzed and projected for an expanded service to a moderately large faculty population.
\end{abstract}

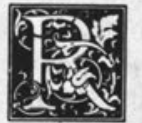

esearchers in the scientific and technical disciplines dedicate considerable time tracking the latest developments in their specialized fields. Assimilating new information acquired through personal networks, scientific meetings, and the literature is essential to advancing their own research and, in turn, the collective knowledge of the field. ${ }^{1}$

Well-known factors, however, stand between researchers and their ability to keep pace with the primary literature. These factors include the substantial volume and growth of literature in science and technology, and the increasing demands to monitor the literature across disciplines. ${ }^{2,3}$ In response, many libraries have developed current awareness or Selective Dissemination of Information (SDI) services. Here, individuals' literature interests are profiled and formulated into computer search statements to be regularly searched against recently published literature. The results of these tailored searches are then routinely forwarded to service participants.

While such services in the academic environment have been received by faculty and others with high praise, the cost of sustaining them has remained an issue. Economies of scale are difficult to achieve in customized services. And when budgets are strained, extending such services may seem beyond the possible, especially to libraries serving large faculty populations.

Addressing these issues, the Science \& Engineering Reference unit at the University of Minnesota developed a model for providing weekly literature updates to faculty. The Current Awareness Service (CAS) used microcomputer databases, a high-speed campus network,

John T. Butler is Reference Librarian and Bibliographer at Science \& Engineering Library, University of Minnesota-Twin Cities, Minneapolis, Minnesota 55455. The author wishes to acknowledge Jerry Stearns and Alan Kaufman of Computer Information Services, University of Minnesota, for their assistance in developing and testing the Automail program used in this project. 
mainframe computing, and electronic mail to realize economies and to expedite dissemination of search results. The Science \& Engineering Reference unit serves over 350 faculty in the Institute of Technology, which is comprised of eleven academic departments covering engineering, computer science, and the physical and earth sciences. A sevenmonth pilot project conducted from August 1991 to February 1992 demonstrated the prospects for offering customized current awareness services at relatively low costs.

\section{PURPOSE}

The purpose of CAS was to supplement the individual faculty member's methods and habits of keeping current by providing a systematic and selective review of recently published literature. ${ }^{4}$ The service was intended to save faculty time, offer extensive coverage of the literature, and incorporate the searching expertise of the professional library staff. CAS was also to complement heavily used document delivery services.

The pilot project model was conceived to serve the moderately large faculty population of the Institute of Technology. To succeed under restrictive budgetary circumstances, operational efficiencies needed to be achieved and costs needed to be minimized.

\section{LITERATURE REVIEW}

The literature contains numerous reports on SDI systems and current awareness services from the 1960 s and early 1970 s. $^{5}$ Overviews and comparisons of methods are reported in more recent years. ${ }^{6}$. Of particular interest were discussions of locally produced, automated methods for providing SDI services which presented economic alternatives to commercial SDI services. The University of Wisconsin-Stout, a prototype service staff developed by which library staff searched commercial online databases and photocopied tables of contents of select journals for local distribution to faculty and staff. ${ }^{7}$ Texas A\&M University experimented with front-end search software to upload profile search state- ments to commercial online databases which, when possible, were searched at off-peak discounted rates. ${ }^{8}$ The most inspiring project was found at Portsmouth Polytechnic. There, a locally produced current awareness service provided researchers with references from CDROM, diskette, and online databases, with results distributed on microcomputer diskettes for loading into their personal bibliographic databases. ${ }^{9}$

Also reviewed was the application of electronic mail to support specific library services. Harry Llull states that using electronic communications over campus networks to perform library functions is not only efficient but also works to penetrate the physical and organizational barriers of being in different buildings and being members of different departments. ${ }^{10} \mathrm{Mi}$ chael Buckland provides a taxonomy for the integration of electronic mail in libraries. His framework suggests numerous possibilities for the application of e-mail to services, including the transmission of tailored information updates to users." The use of electronic networks for transmitting information resources is not uncommon in large, decentralized corporate organizations. ${ }^{12}$ At Lehigh University, the use of electronic networks for transmitting documents, literature searches, and other information products is planned as part of the libraries' integrated information services. ${ }^{13}$ In this review, specific academic library application of electronic mail for current awareness or SDI purposes was not identified.

\section{OPERATIONAL REQUIREMENTS}

Considering the SDI designs reviewed, five requirements of the prospective model were identified:

1. A microcomputer bibliographic database with minimal indexing lag time, a frequent publication rate (at least monthly), and sufficient literature coverage in the disciplines of concern. The rationale for selecting a microcomputer database over other platforms was the cost stability, which was ensured by a flat rate subscription agreement, and inhouse control, which was viewed 
as key to shaping the service to local needs. The increasing selection of major bibliographic databases for microcomputer searching (CD-ROM, diskette) was also influential.

2. A method to create high quality literature profiles for individual faculty. Results here would, more than anything else, affect the value of the service to participants in the project. ${ }^{14}$

3. The electronic delivery of search results which would expedite perishable information to participants, provide data in a format ready for electronic postprocessing, and minimize library staff processing and handling.

4. A systematic method for periodic review and updating of profiles.

5. Communication between faculty participants and librarians about issues relating to the service.

\section{FACULTY PARTICIPANTS}

The faculty of the Department of Electrical Engineering were selected as the test population for the pilot project. These faculty members were noted for their interdisciplinary research (an attribute which would test the literature coverage of the selected database) and were established users of electronic mail. Of the fifty faculty members in Electrical Engineering, twenty-one, or 41 percent, agreed to participate in the pilot project.

\section{METHODOLOGY}

To initiate profiling, participants were sent a self-reporting questionnaire that asked them to:

1. Detail the subject matter they wished to include in their profiles and to provide appropriate keywords and phrases describing the subject matter.

2. Provide titles of journals for which they wanted complete table of contents listings.

3. Provide names of authors whose publications they wished to track.

4. Specify language restrictions to be applied to search results.

After reviewing completed questionnaires, a librarian telephoned or e- mailed each faculty participant. This proved essential for further defining the context and scope of specific literature interests and for clarifying ambiguous written responses on the questionnaire.

Selected as bibliographic databases for the project were the weekly issued Current Contents on Diskette-Physical, Chemical, and Earth Sciences, and Current Contents on Diskette-Engineering, Tichnology and Applied Sciences, (both databases referred to as CCOD hereafter). The databases met the operational requirements previously identified ${ }^{15}$ Also, the intended use of the databases for this project fit within the vendor's single work station subscription agreement. ${ }^{16}$

Using profile information gathered through questionnaires and follow-up correspondence, logical search statements for each participant were formulated and saved with the CCOD software, which is a function similar to search/save on other systems. A weekly routine was then initiated. On receipt, new CCOD issues were loaded into a microcomputer, an IBM-compatible with a $20 \mathrm{MHz} 386$ processor. Each profile was run against the two databases, with search results from both downloaded into a single text file. Downloaded files were each assigned a control name that would later be referred to by other computer programs in the e-mail procedure. Downloaded files were submitted to error checking procedures to identify potential operator error and were then ready for transmission to participants.

Key to the e-mail component of the model was the University's Digital Equipment Corporation VAX 6000-520 running the VMS 5.4 operating system and VAX/VMS Mail Utility. (It is suspected that comparable hardware may be substituted.) The VAX is connected to the University Campus Internet, external Internets, Bitnet, and DECnet. The Campus Internet used in this project is a large Ethernet-like network that makes it possible to provide high-speed access to most campus mainframe systems from almost any computer on campus, including microcomputers in local area networks that are in turn connected to it. 
To begin the mailing procedure, the microcomputer text files were uploaded to the VAX, using a high-speed connection to the campus Internet. Telnet and file transfer protocol (FTP) facilitated terminal emulation and file transfer, respectively. ${ }^{17}$ Data were uploaded at a rate averaging $40 \mathrm{~KB}$ to $64 \mathrm{~KB}$ per second. When all files were confirmed as sent to the VAX, the files were then sent to participants, using the VAX/VMS Mail Utility and a command program created for this project called Automail.

In contrast to standard e-mail distribution lists, which send one message to many individuals, Automail sends en masse numerous unique messages or files to numerous unique addresses. Used with supporting command and data files, Automail links the names of each uploaded file to the electronic address of the participant to which it is destined..$^{18}$ Once the match is made, the program instructs the mail utility to send the file to the specified address. All files are sent routinely without operator intervention. An onscreen status report summarizes the mailing operations to ensure that all files are sent. Combined file transmission activities, which included uploading and mailing, averaged fifteen seconds per data file. These efficiencies firmly established the model's technical feasibility of extending the service to a larger faculty population.

\section{UPDATING PROFILES}

While requests from participants to modify search profiles were encouraged at any time, an optional review procedure was also established. Every three months, each participant was electronically sent his or her current profile and an update form to specify desired modifications. To do this efficiently, DOS batch files were used to assemble individual profiles and update forms into single text files, which were then transmitted to participants using Automail. Those electing to modify their profiles returned specifications either electronically or as an edited printout. The next literature update then reflected the changes made to the profile search statement.

\section{RESULTS}

For seven months, twenty-one faculty members received a weekly average of fifty-three citations from CCOD-Physical, Chemical, and Earth Sciences, and twentynine citations from CCOD-Engineering, Technology and Applied Sciences. Although anticipated, the heavy retrieval of physics literature confirmed the need for interdisciplinary literature coverage for this group of engineering faculty.

The role CAS played in personal current awareness styles varied among participants. For some, CAS detected research that was unpredictably and infrequently reported in the literature, such as devices for the acoustic detection of termites. Others, nearly 25 percent, wished to receive unfiltered contents listings from selected journal titles. The intent here was to support what Eugene Garfield has referred to as "systematic serendipity" or the organized process of information discovery. ${ }^{19}$ One participant said, "Reviewing article titles from the major journals is the only way to find what I'm looking for. I can't design a keyword search strategy for crazy new ideas." For another, CAS provided contents listings to two journals to which, at a combined subscription rate of $\$ 8,900$ per year, the library did not subscribe but could request individual articles through other suppliers.

Requests for customized packaging of search results were accommodated whenever possible. For example, one participant wanted results batched into sets based on his reviewing priorities. This allowed results needing immediate review to come separate from results that could be reviewed when time permitted. Others requested results sent in particular file formats to facilitate downloading into their bibliographic software packages. Customizing results was an opportunity to add value to the service. It did not appreciably drag on the system's efficiency.

\section{EVALUATION}

Participants were surveyed to determine the service's performance and 
value in light of their current awareness needs. Fifteen of twenty-one, or 72 percent, of the participants responded. A summary of responses is provided in table 1.

The survey also solicited comments on the service's strengths and weaknesses. Most frequently cited strengths were savings of time and the identification of relevant publications that would otherwise be overlooked. The electronic delivery of results was praised as convenient and as lending itself to subsequent retrieval and processing of search results loaded into personal files. Also, the use of e-mail to specify profile modifications was considered efficient and responsive. It is believed that the active role participants played in periodically reviewing and rejuvenating their own profiles raised the level of vested interest in the service and, consequently, the quality of the results.

Among the cited weaknesses was excessive quantities of citations and, in some instances, duplicate citations received. The overabundance of citations was frequently attributed to profiles that requested full contents listings of such titles as Physical Review-B and the Journal of Applied Physics, which typically have 100 to 300 articles per issue. On realizing this, many participants adjusted their profiles. Duplicate citations resulted from overlapping coverage of several journal titles by the two sections of $C C O D$. Additional programming to prevent duplicate citations was later applied to profiles where this was a problem. ${ }^{20}$

\section{costs}

Also analyzed were the direct costs of the pilot project, which were defined as expenses that would have not occurred without the project. On that basis, direct costs of providing the service to additional faculty were projected. Both actual and projected costs are presented in table 2 . As shown, direct costs per faculty member per week are projected to decrease as the number of participants increases.

Labor of professional staff and that of clerical staff was analyzed, too, and is presented in table 3 . The values shown
TABLE 1

EVALUATION SUMMARY

$(\mathrm{N}=15)$

\begin{tabular}{lc}
\hline Response & $\%$ \\
\hline Overall performance of service & \\
Excellent & 46.6 \\
Good & 40.0 \\
Fair & 13.3 \\
Poor & 0.0
\end{tabular}

Relevance of citations sent

Mostly relevant

Often relevant

Sometimes relevant

Seldom relevant

Quantity of citations sent

Too much

About right

Too little

Frequency of updating profile to keep up with research focus

Less than once a year

Once a year

Every 6 months

Every 3 months

Presently downloading CAS results into personal database

Yes

I don't download but would like to

No, I have no interest

Interest in group profiles in your department
A lot of interest
Moderate interest
40.0
Slight interest
46.6
No interest

Importance of the Current Awareness Service continuing

Very important

Important

Slightly important

Unimportant 
TABLE 2

DIRECT COSTS-ACTUAL AND PROJECTED (IN DOLLARS PER FACULTY MEMBER PER WEEK)

\begin{tabular}{lcccc}
\hline & \multicolumn{4}{c}{ Number of Faculty } \\
\cline { 2 - 5 } Item & 21 (actual) & 50 & 100 & 200 \\
\hline Current contents: & $\$ .36$ & .15 & .08 & .04 \\
$\quad$ Physical/Chemical/Earth sciences & & & & \\
Current contents: & .36 & .15 & .08 & .04 \\
$\quad$ Engineering/Technology/Applied sciences & .28 & .28 & .27 & .25 \\
Mainframe computing & .07 & .03 & .02 & .01 \\
Microcomputer LAN access & .01 & .01 & .01 & .01 \\
Supplies (floppy disks, paper files) & $\$ 1.08$ & .62 & .46 & .35 \\
Total & & & & \\
\hline
\end{tabular}

*These databases are part of the units's reference collection, as each is loaded on a public access microcomputer. Funding for them would likely continue, regardless of this project. Therefore, whether their costs belong in full, in part, or in any way to the project is subject to discussion.

**Potential, not actual, costs for mainframe computing are shown. Actual costs to the project was
$1 / 20$ of the amount represented. A university computing grant allows the library $\$ 1,000$ of
computing time for $\$ 50$ actual expenditure. Comparable grants are available at other universities.

for professional staff time are based on the average total time commitment per participant over the test period, then calculated to a per week/per participant unit. Note, though, that the activities of professional staff tended not to be routine or evenly distributed over time, but rather heavily concentrated in the

\section{TABLE 3}

LABOR (IN HOURS PER FACULTY MEMBER PER WEEK)

\begin{tabular}{lcc}
\hline Activity & $\begin{array}{c}\text { Professional } \\
\text { Staff }\end{array}$ & $\begin{array}{c}\text { Clerical } \\
\text { Staff }\end{array}$ \\
\hline $\begin{array}{l}\text { Profiling faculty } \\
\begin{array}{l}\text { Creating search } \\
\text { profiles }\end{array}\end{array}$ & .03 & - \\
$\begin{array}{l}\text { Communications with } \\
\text { participants }\end{array}$ & .01 & - \\
$\begin{array}{l}\text { Running profiles/ } \\
\text { downloading } \\
\text { results }\end{array}$ & .01 & - \\
$\begin{array}{l}\text { Error checking } \\
\text { Mainframe computing } \\
\quad(\mathrm{e}-\text { mail) }\end{array}$ & - & .05 \\
$\begin{array}{l}\text { Record keeping } \\
\text { Total }\end{array}$ & - & .01 \\
\hline
\end{tabular}

earlystages of an individual's participation (in profiling and creation of search profileactivities).

The requirements of professional time per participant are projected to remain the same, regardless of the number of participants, as profiling activities were, and would continue to be, largely unaffected by automation. However, reductions in clerical staff time may be realized through additional automation. For example, an auxiliary program to run the profiles in a batch process would virtually eliminate the largest expenditure of clerical staff time and would significantly reduce indirect costs.

Assuming rates of $\$ 15$ per hour for professional staff and $\$ 8$ per hour for clerical staff, the total cost per participant per week was $\$ 2.55$ (for twenty-one participants). The projected total cost of serving larger numbers of individuals are $\$ 2.09$ per participant/per week for fifty participants; $\$ 1.93$ for 100 ; and $\$ 1.82$ for 200. Depending on the total number of participants, labor accounts for 58 to 81 percent of the total cost. This is important to note because many cost analyses of current awareness services represent only direct costs, as usually paid to a 
commercial vendor, and do not factor the costs of profiling activities or associated clerical activities.

The unit costs of CAS held clear economic advantage over delivering similar services through commercially based SDI services. To compare, a competitive online vendor offers SDI updates in Current Contents for 75 cents per bibliographic citation, plus $\$ 5.50$ per weekly update, or $\$ 7$ per biweekly update. A realistic portrayal of costs, using commercial services, is seen in the University of WisconsinStout program, which reported $\$ 17$ per month per participant for SDI updates and citation charges alone. ${ }^{21}$ Again, these are just the direct costs paid to the vendor and exclude the costs of labor associated with profile creation and management and handling of search results.

\section{CONCLUSION}

Faculty and researchers in many disciplines require a constant flow of current and often highly specialized information. An enterprising library response is to develop ongoing individualized information services. Though challenging economically, certain technological efficiencies present opportunities to minimize costs. Here, the CAS pilot project demonstrated an economical method for providing current awareness services by using relatively inexpensive microcomputer databases and e-mail.

The service was well received. A frequently voiced reaction by faculty was that the service exceeded their expectations of what the library could or would be willing to do for them as individuals. This spoke not only to the primary function of the service- providing tailored literature searches-but also to accommodating requests for special formatting and packaging of results. In evaluation, the service was rated highly overall, and as an indicator of its value, three-quarters of respondents reported the continuation of the service as "very important to their academic activities." Faculty's embrace of electronic mail as the conduit for the service was instru- mental in achieving operational efficiency. Because of that, expanding the service to include the larger faculty population can proceed.

It is believed that the active role participants played in periodically reviewing and rejuvenating their own profiles raised the level of vested interest in the service and, consequently, the quality of the results.

Also key to expanding the service is the staff's view that providing current awareness services to faculty fits well within their roles as librarian-academic department liaisons. A clear benefit to librarians is that information gathered in the initial and ongoing profiling activities can be applied to their collection development planning. As a logical extension of the service, future involvement of the staff may include advising faculty on the selection and implementation of personal bibliographic database software for the postprocessing of CAS results. Also, the automatice-mail program implemented here brings to mind numerous possibilities for disseminating other custom-generated information sources to faculty, researchers, and research groups.

Of the many reasons why customized information services deserve serious consideration in the academic library, perhaps one of the best, yet least recognized, is the framework such services provide for building productive faculty-librarian relationships. Robert Grover and Martha Hale propose that academic librarians transcend their traditional reactive or passive modes of service and become integral players in the research efforts of faculty. Only then will librarians really understand the research process and, consequently, the information resources and services needed to support it. ${ }^{22}$ By extending individualized services to faculty, the CAS pilot project became an instrument for developing such involvement. 


\section{REFERENCES AND NOTES}

1. Scientists' use of formal and informal channels of communicating research results is investigated by F. W. Lancaster and Linda C. Smith, "Science, Scholarship and the Communication of Knowledge," Library Trends 27 (Winter 1978): 367-88; Robert S. Allen, "Physics Information and Scientific Communication: Information Sources and Communication Patterns," Science \& Technology Libraries 11 (Spring 1991): 27-38; and by William D. Garvey, Communication: The Essence of Science (Elsford, N.Y.: Pergamon Press, 1979).

2. Derek J. de Solla Price, Little Science, Big Science . . . and Beyond (New York: Columbia Univ. Pr., 1986), 1-29; Charles L. Bernier and A. Neil Yerkey, Cogent Communication: Overcoming Reading Overload (Westport, Conn.: Greenwood, 1979), 31-44; Wilfred Ashworth, "The Information Explosion," Library Association Record 76 (Apr. 1974): 63-8; and J. M. Ziman, "The Proliferation of Scientific Literature: A Natural Process," Science 208 (Apr. 25, 1980): 369-71. A contrasting viewpoint is presented by Eugene Garfield, "In Truth, The 'Flood' of Scientific Literature Is Only a Myth," The Scientist 5 (Sept. 2, 1991): 11, 25.

3. Though there are unprecedented degrees of specialization in the sciences, the amount and range of literature required have increased because of the intertwining of disciplines. See Garvey, Communication, 107; Lancaster and Smith, "Science, Scholarship and the Communication of Knowledge," 382; and H. W. Koch, The Federal Government and Research Museums and Libraries of the Future (New York: American Institute of Physics, Information Division, 1970).

4. This is similar to stated purposes of many current awareness services, such as those presented by H. P. Luhn, "Selective Dissemination of New Scientific Information with the Aid of Electronic Processing Equipment," American Documentation 12 (Apr. 1961): 131-38; and those reviewed by John H. Schneider, "Selective Dissemination and Indexing of Scientific Information," Science 173 (July 23, 1971): 300-8.

5. Van A. Wente and Gifford A. Young, "Current Awareness and Dissemination," Annual Review of Information Science and Technology 5 (1970): 259-95; Roger L. Meyer, Amy J. Meskin, John J. Mracek, James H. Schwartz, and Emma C. Wheelihan, "A Systematic Approach to Current Awareness and SDI," Journal of Chemical Documentation 11 (February 1971): 19-24; Edward M. Housman, "Selective Dissemination of Information," Annual Review of Information Science and Technology 8 (1973): 221-41; and George R. Mauerhoff, "Selective Dissemination of Information," Advances in Librarianship 4 (1974): 25-62.

6. Giuliana A. Lavendel, "SDI in Scientific and Technical Libraries: An Overview of the Options, Science and Technology Libraries 2 (Fall 1981): 3-16; Tom Whitehall, "Alternatives for Current Awareness Services," in Practical Current Awareness Services from Libraries, ed. Tom Whitehall (Brookfield, Vt.: Gower Publishing, 1986), 1-14; Sushila Kapadia and Janice Rettino, "SDI Service at the Library of the College of Medicine and Dentistry of New Jersey: Developments and Future Trends," Science and Technology Libraries 2 (Fall 1981): 17-29.

7. John J. Jax and Van C. Houlson, "A Current Awareness Service for Faculty and Staff: The Stout Experience," College \& Research Libraries 49 (Nov. 1988): 514-22.

8. William R. Kinyon and Rosemary Loomis, "Current Awareness: Are Front-End Systems the Answer?" in Proceedings of the Eighth National Online Meeting, New York, May 5-7, 1987, comp. by Martha E. Williams and Thomas H. Hogan (Medford, New Jersey: Learned Information, 1987), 245-51.

9. Terry Hanson, "The Electronic Current Awareness Service and the Use of Pro-Cite at Portsmouth Polytechnic," in Proceedings of the 14th International Online Information Meeting, London, Dec. 11-13, 1990, ed. David I. Raitt (Medford, N.J.: Learned Information, 1991), 277-87.

10. Harry Llull, "Meeting the Academic and Research Information Needs of Scientists and Engineers in the University Environment," Science and Technology Libraries 11 (Spring 1991): 83-90.

11. Michael K. Buckland, "Combining Electronic Mail with Online Retrieval in a Library Context," Information Technology and Libraries 6 (Dec. 1987): 266-71. 
12. Giuliana Lavendel, "Xerox Network: A True Believer's View," Science and Technology Libraries 8 (Winter 1987/1988): 31-39; Donald T. Hawkins, "Use of Machine-Readable Databases to Support a Large SDI Service," Information Processing and Management 21 (1985): 187-204; W. David Penniman and Donald T. Hawkins, "The Library Network at AT\&T," Science and Technology Libraries 8 (Winter 1987/88): 3-24; and Helen M. Manning, "WE DELIVER: Libraries and Information Delivery at Texas Instruments," Science and Technology Libraries 11 (Fall 1990): 69-76.

13. Berry G. Richards and Jean M. Johnson, "Electronic Delivery of Information via a Campus-Wide Network," Science and Technology Libraries 11 (Fall 1990): 5-17.

14. SDI pioneer Luhn recognized the importance of carefully conducted profiling activities to SDI services back in 1961: "The creation and maintenance of profiles of the participants of the service is the most important and, at the same time, the most critical task within the system. People's interests vary widely as to scope and breadth, and there are no easy means, short of human analysis, to define those interests." See Luhn, "Selective Dissemination," 137.

15. For a review of CCOD, see J. H. Powell, "Current Contents on Diskette: A Review," CD-ROM Professional 3 (Sept. 1990): 39-44. Also note that, in 1991, Current Contents with Abstracts were commercially introduced, providing author-supplied abstracts for several sections of CCOD.

16. The Institute for Scientific Information, producers of $C C O D$, considered electronic distribution of search results acceptable under the single work station subscription agreement so long as data transmitted was directed to individuals within the organization holding the subscription and as long as the CCOD database, or any part thereof, did not reside on a network that would allow multiple user access.

17. Telnet is a network program that allows a local and remote computer, which may be of a variety of terminal and computer types, to communicate over the Internet. File Transfer Protocol (FTP) is the protocol and program used to transfer files between Internet systems. Files may consist of text, graphics, sound, software, or other information types.

18. Supporting files for Automail were a command file which defines an alias e-mail address for each participant. Here, the alias is identical to the file name assigned to the microcomputer files as it is downloaded from the bibliographic database. Also used was a data file, listing the aliases through which the Automail program loops.

19. Eugene Garfield, Essays of an Information Scientist vol. 1 (Philadelphia: ISI Press, 1977), 37.

20. Current Contents on Diskette search software version 3.0 supports multiple issue searching, systematically eliminating duplicate citations between simultaneously searched sections.

21. Jax and Houlson, "A Current Awareness Service for Faculty and Staff," 520-21.

22. Robert Grover and Martha L. Hale, "The Role of the Librarian in Faculty Research," College \& Research Libraries 49 (Jan. 1988): 9-15. 


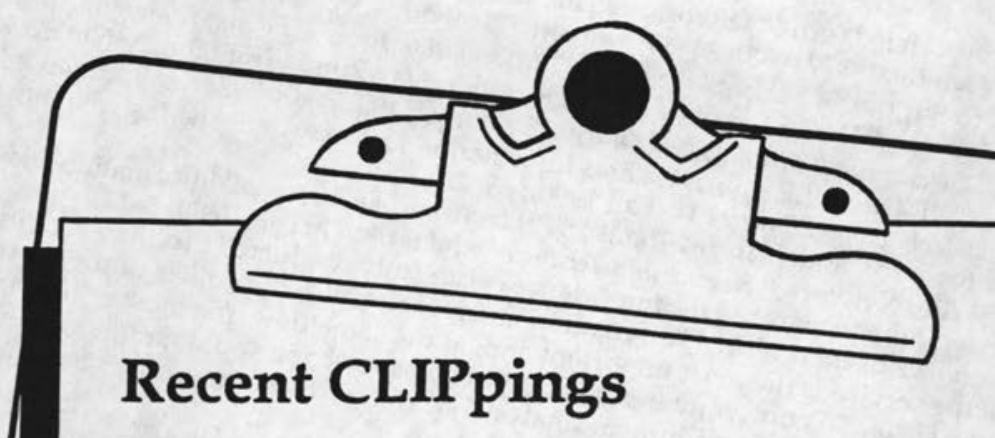

College Library Information Packets (CLIP Notes) collect data and sample documents for use by college and small university libraries to establish or refine services and operations. CLIP Notes are prepared by the College Libraries Section.

Interlibrary Loan in College Libraries. CIIP Note "16, compiled by Roxann Bustos.

\$34.50; ACRL member \$28.75 148p. 0-8389-7652-2 1993

Database Searching in College Libraries. CIIP Note "15, compiled and written by Sarah Pederson.

\$29.95; ACRL member \$24.95 124p. 0-8389-7651-4 1993

Audiovisual Policies in College Lbraries. CUIP Note \#14, compiled by Kristine Brancolini.

\$21.95; ACRL member \$18.65 152p. 0-8389-7495-3 1991

College Library Newsletters. CIIP Note \#13, compiled by Patricia Smith Butcher and Susan McCarthy Campbell.

\$18.65: ACRL member \$15.35 154p. 0-8389-7445-7 1990

Performance Appraisal in Academic Lbraries. C.IP Note "12. compiled by Barbara Williams Jenkins with the assistance of Mary $L$. Smalls.

\$18.64; ACRL member \$15.35 128p. 0-8389-7444-9 1990

Collection Development Policies for College Lbraries. CIIP Note "11, compiled by Theresa Taborsky.

\$26.35; ACRL member \$21.94 175p. 0-8389-7295-0 1989

\section{Association of College and Research Libraries
A division of the American Library Association
c/o ALA Publishing Services, Order 50 East Huron Street - Chicag, Order Department}

